\title{
Conditioning-specific reflex modification of the rabbit (Oryctolagus cuniculus) nictitating membrane response: US intensity effects
}

\author{
MATTHEW A. SEAGER, CARRIE A. SMITH-BELL, and BERNARD G. SCHREURS \\ Blanchette Rockefeller Neurosciences Institute \\ and West Virginia University School of Medicine, Morgantown, West Virginia
}

\begin{abstract}
Conditioning-specific reflex modification (CRM) of the rabbit's nictitating membrane response (NMR) describes changes in responding to an unconditioned stimulus (US) when the rabbit is tested in the absence of the conditioned stimulus. Specifically, after at least 3 days of tone-electrical stimulation pairings, responses to the US increase in size, especially at intensities weaker than the training intensity. CRM is similar to classical conditioning in that it is a function of the strength of conditioning, it can be extinguished, and it can be generalized from one stimulus to another. To compare CRM and classical conditioning further, we conducted three experiments to examine the effects of US intensity $(1.0,2.0$, and $4.0 \mathrm{~mA})$ on CRM. CRM was weak following conditioning with $1.0 \mathrm{~mA}$ and extremely strong following conditioning with $2.0 \mathrm{~mA}$ and $4.0 \mathrm{~mA}$. The data suggest that CRM is a function of US intensity and have implications for posttraumatic stress disorder, a disorder potentially modeled by CRM.
\end{abstract}

Substantial evidence indicates that an unconditioned response (UR) can be modified during pairings of a conditioned stimulus (CS) and an unconditioned stimulus (US) (Canli, Detmer, \& Donegan, 1992; Flaten \& Powell, 1998; Marcos \& Redondo, 1999; Nowak, Goodell-Marshall, Kehoe, \& Gormezano, 1997; Weisz \& McInerny, 1990). However, modification of the UR is attributable to the presence of the CS. These CS-mediated changes in the UR result from both nonassociative and associative processes (see Canli et al., 1992, for review). For example, a tone may facilitate the rabbit nictitating membrane response (NMR) the first time the tone and air puff (AP) are presented together, before any association between the two stimuli can have formed (Ison \& Leonard, 1971; Weisz \& Walts, 1990). On the other hand, a tone may decrement a UR once the tone and the US have been paired repeatedly and an association has been formed (Donegan, 1981). In each of these experiments, the focus has been on the effects of the CS on the UR, and consequently, measures such as response amplitude have been assessed in the presence of the CS.

Conditioning-specific reflex modification (CRM) of the rabbit NMR occurs when CS-US pairings modify responding to the US when the US is presented by itselfin the absence of the CS. Specifically, after at least 3 days of tone-electrical-stimulation (ES) pairings, responses to the US increase in amplitude, peak latency, and area, es-

The present research was supported in part by National Institutes of Health Grant MH 64715 to B.G.S. and AG20461 to M.A.S. Correspondence concerning this article should be addressed to B. G. Schreurs, Blanchette Rockefeller Neurosciences Institute and Department of Physiology and Pharmacology, P. O. Box 9302, West Virginia University, Morgantown,WV 26506 (e-mail: bschreurs@hsc.wvu.edu). pecially at intensities weaker than the training intensity. We have previously reported that CRM is a function of the strength of conditioning, can survive extinction of the CR, can be extinguished with US-alone presentations, can be generalized from ES to AP, and may be related to conditioned fear (Buck, Seager, \& Schreurs, 2001; Schreurs, Oh, Hirashima, \& Alkon, 1995; Schreurs, Shi, Pineda, \& Buck, 2000). Our original observation of CRM was confirmed by Gruart and Yeo (1995) and has since been replicated by Wikgren, Ruusvirta, and Korhonen (2002), who have begun to explore its neural substrates.

One of the behavioral laws of classical conditioning is that the rate and level of conditioning increase as a function of US intensity (Fitzgerald \& Teyler, 1970; Gormezano, 1966; Smith, 1968). We have suggested previously that CRM may be similar to, but not necessarily isomorphic with, classical conditioning(Buck et al., 2001; Schreurs et al., 2000). For example, although CRM is a function of the strength of classical conditioning, it is not eliminated when conditioning is eliminated or extinguished by CSalone extinction. It is eliminated or extinguished, however, by presenting the US alone (Schreurs et al., 2000). CRM is generalized from ES to AP but is not generalized from AP to ES, even though conditioning occurs to comparable levels with either ES or AP as the US (Buck et al., 2001). Finally, significant levels of CRM can be obtained only at high AP intensities, even though conditioning is supported by lower AP intensities (Buck et al., 2001). The purpose of the present experiments was to further detail the CRM effect so that we might continue to compare and contrast it with classical conditioning. In these experiments, we determined the effects of manipulating the ES training intensity $(1.0,2.0$, and $4.0 \mathrm{~mA})$ on the ability to detect CRM and on the strength of the phenomenon. 


\section{EXPERIMENT 1}

In previous CRM experiments, we found that although conditioning is supported by various levels of AP intensity, significant levels of CRM can be obtained only after conditioning at high AP intensities (Buck et al., 2001). The fact that it was possible to obtain a maximal level of conditioning at a low AP intensity without obtaining significant CRM suggested that CRM was not simply the generalization of a CR from the CS to the US (Gruart \& Yeo, 1995). Given that ES can support heart rate conditioning but AP cannot and that heart rate conditioning is used as an index of conditioned fear (McEchron, McCabe, Green, Llabre, \& Schneiderman, 1991), we suggested that there may be a conditioned fear component to classical conditioning of the rabbit NMR when a relatively intense/aversive US is used (e.g., ES and strong AP; Buck et al., 2001). The present experiment was designed to determine whether CRM could be obtained with a US that was strong enough to support a substantial level of conditioning but half the strength of the $2.0-\mathrm{mA}$ value normally used to obtain CRM, and thus a US that was half as intense and presumably less aversive.

\section{Method}

Subjects. Sixteen male New Zealand White rabbits (Oryctolagus cuniculus ) supplied by Harlan (Indianapolis) weighed approximately $2.0-2.2 \mathrm{~kg}$ at the beginning of the experiment. The animals were housed in individual cages, given free access to food and water, and maintained on a 12:12-h light:dark cycle. They were maintained in accordance with guidelines issued by the National Institutes of Health.

Apparatus. The apparatus and recording procedures for the NMR have been detailed by Schreurs and Alkon (1990), who modeled their apparatus after those described by Gormezano (Coleman \& Gormezano, 1971; Gormezano, 1966). In brief, each subject was restrained in a Plexiglas box and trained in a sound-attenuating, ventilated chamber (Coulbourn Instruments, Model E10-20). A stimulus panel containing a speaker and houselights (10-W, 120-V incandescent lamps) was mounted at a $45^{\circ}$ angle, $15 \mathrm{~cm}$ anterior to and $15 \mathrm{~cm}$ above the subject's head. An ambient noise level of $65 \mathrm{~dB}$ in each chamber was provided by an exhaust fan. Periorbital ES was delivered by a programmable two-pole shocker (Coulbourn Instruments, Model E1335) via stainless steel Autoclip wound clips positioned $10 \mathrm{~mm}$ below and $10 \mathrm{~mm}$ posterior to the dorsal canthus of the right eye.

Details of transducing NM movements have been reported previously (Gormezano \& Gibbs, 1988; Schreurs \& Alkon, 1990). In short, a hook connected to an L-shaped lever containing a freely moving ball and socket joint was attached to a 6-0 nylon loop sutured into, but not through, the NM. The other end of the lever was attached to a rotary encoder (Vernitron Corp., Model VOE05-256), which in turn was connected to a 12-bit analog-to-digital converter (5-msec sampling rate; $0.05-\mathrm{mm}$ resolution). Individual analog-todigital outputs were stored on a trial-by-trial basis for subsequent analysis. Data collection, data analysis, and stimulus delivery were accomplished using a LabVIEW system (National Instruments).

Procedure. The rabbits were randomly assigned to two groups that received 1 day of adaptation, one 80-trial session of ES US pretesting, six daily sessions of paired CS-US presentations (paired, $n=8$ ) or unpaired CS and US presentations (unpaired, $n=8$ ) with an ES US, followed by an 80-trial session of ES US posttesting.

On adaptation day, the rabbits were prepared for ES and recording of NM movement and then adapted to the training chambers for the length of time of subsequent training sessions $(80 \mathrm{~min})$. On both
ES pretest and posttest days the subjects received a total of 80 trials of ES stimulation presented at an average intertrial interval (ITI) of $60 \mathrm{sec}$ (range, $50-70 \mathrm{sec}$ ). Each trial involved the presentation of 1 of 20 possible combinations of stimulus intensity $(0.1,0.25,0.5,1.0$, or $2.0 \mathrm{~mA})$ and duration $(10,25,50$, or $100 \mathrm{msec})$. Four separately randomized sequences of the 20 stimulus combinations were presented on each testing day, with the restriction that the same intensity or duration could not occur on more than 3 consecutive trials.

Each of the six paired-conditioning sessions consisted of 80 presentations of a $400-\mathrm{msec}, 1-\mathrm{kHz}, 82-\mathrm{dB}$ tone CS that coterminated with a $100-\mathrm{msec}, 1.0-\mathrm{mA}$ ES US (i.e., 300-msec interstimulus interval [ISI]). Paired stimulus presentations were delivered, on average, every $60 \mathrm{sec}$ (range, 50-70 sec). Sessions for unpaired subjects consisted of $80 \mathrm{CS}$-alone and 80 US-alone presentations that occurred in an explicitly unpaired manner delivered, on average, every $30 \mathrm{sec}$ (range, 20-40 sec).

A CR was defined as any extension of the NM exceeding $0.5 \mathrm{~mm}$ that was initiated after CS onset but prior to US onset. A UR was defined as any extension of the NM exceeding $0.5 \mathrm{~mm}$ that was initiated within $300 \mathrm{msec}$ of US onset (i.e., the CS-US ISI used to score CRs during pairings). The UR criterion was based on the observation that, following CS-US pairings, posttest URs at lower US intensities had onset latencies that fell into the range of latencies for CRs (Schreurs et al., 2000). The amplitude of a response was scored in millimeters as the maximum extension of the NM. The onset latency of a response was identified as the latency in milliseconds from stimulus onset at which a response rose $0.1 \mathrm{~mm}$ above the baseline. The peak latency of a response was determined as the latency in milliseconds from stimulus onset for maximum extension of the NM. The area of a response was calculated as the total area under the response curve from US onset to the end of the trial.

Response topographies for each of the US intensities were averaged across subjects and examined for differences by comparing the shape of the averaged response. To provide a statistical measure of the shape of an averaged response, we analyzed for symmetry (skew) and tail size (kurtosis). A significant positive skew value indicates that the response has a peak toward the beginning of the trial, and a signif icant negative value indicates that the response has a peak more toward the end of the trial. A significant positive kurtosis value indicates that the response has a long tail, and a significant negative value indicates that the response has a short tail. A skew coefficient is considered significant if the absolute value of skew divided by the standard error of skew is greater than 2, and a kurtosis coefficient is considered significant if the absolute value of kurtosis divided by the standard error of kurtosis is greater than 2 (Systat 8.0, SPSS Inc., 1998). Our previous research indicated that URs on pretest reached their peak just after US onset with a long tail to the right. Such response topographies would yield high positive values for both skew and kurtosis. However, following CS-US pairings, URs tend to have peaks that are larger and shifted to the right, yielding lower and even negative values for both skew and kurtosis.

\section{Results}

Conditioning. One paired rabbit did not acquire CRs and was dropped from the analysis. Figure 1 shows the mean $( \pm S E M)$ percent CRs for the remaining animals in the paired and unpaired groups across the 6 days of stimulus presentations. As can be seen, the paired animals began at a level of about $14 \%$ CRs and showed a gradual increase in conditioned responding, reaching an asymptotic level of $95 \%$ CRs on Day 4. In contrast, the unpaired animals showed virtually no sign of responding to the CS. An analysis of variance (ANOVA) revealed significant main effects of group and day $[F(1,13)=204.07, p<.001$, and 


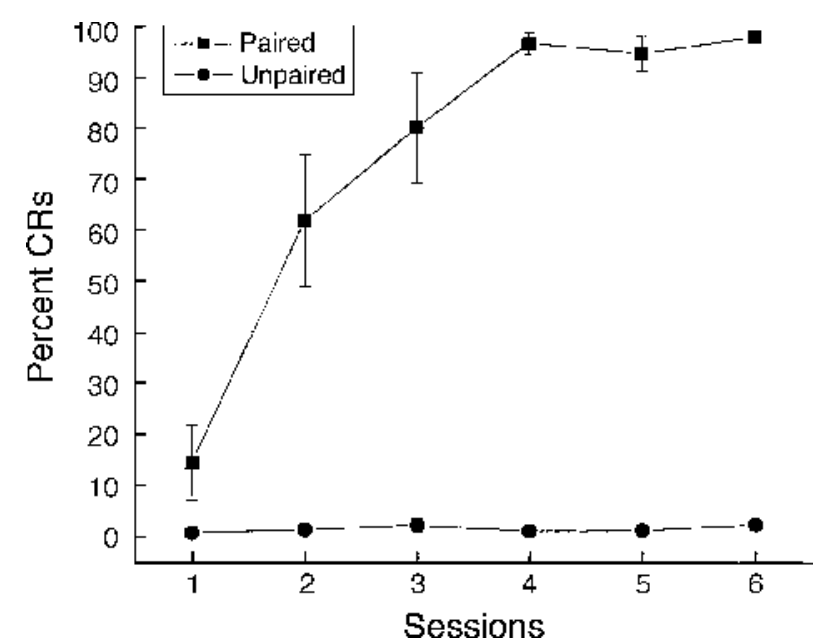

Figure 1. Mean ( $\pm S E M)$ percent $C R s$ for animals in the paired and unpaired groups across the 6 days of stimulus presentations with a 1.0-mA US. Each of the six paired-conditioning sessions consisted of 80 presentations of a $400-\mathrm{msec}, 1-\mathrm{kHz}, 82-\mathrm{dB}$ tone CS that coterminated with a 100-msec, 1.0-mA ES US. Sessions for unpaired subjects consisted of $80 \mathrm{CS}$-alone and 80 US-alone presentations that occurred in an explicitly unpaired manner. Note that all $S E M$ values are included but are often smaller than the data points.

$F(5,65)=26.93, p<.001$, respectively $]$, as well as an interaction of the two factors $[F(5,65)=25.79, p<.001]$.

US testing. Figure 2 shows averaged response topographies on US-alone pretest (dotted lines) and posttest trials (solid lines) for the paired and unpaired groups. The plots are arranged in descending order of US intensity $(2.0 \mathrm{~mA}$ to $0.1 \mathrm{~mA}$ ) and collapsed across US duration. The figure depicts simple uniphasic positively skewed URs to all US intensities for both paired and unpaired groups on pretest and posttest, with the exception of an increase in the size and shape of URs for rabbits in the paired group at posttest US intensities of $0.5 \mathrm{~mA}$. An analysis of skew confirmed that there was significant positive skew for all averaged responses (skews $>3.4$ ), with the exception of the posttest averaged response of paired subjects to a US of $0.5 \mathrm{~mA}$ that had no positive skew (skew $=-0.88$ ) and significant negative kurtosis (kurtosis $=-2.99$ ).

Analysis of the mean UR measures (frequency, onset latency, amplitude, peak latency, and area) across US intensities during pretest and posttest for the paired group indicated that there was a significant increase in the frequency of URs on posttest at both $0.5 \mathrm{~mA}[F(1,13)=9.07$, $p<.05]$ and $1.0 \mathrm{~mA}[F(1,13)=6.56, p<.05]$. There was a substantial increase in response amplitude, peak latency, and area at $0.25 \mathrm{~mA}$ on posttest that could not be evaluated statistically because of a lack of responses on pretest. There were no significant differences between URs on pretest and posttest for unpaired subjects.

\section{Discussion}

Taken together, the results of Experiment 1 provide weak evidence of CRM and show that training to an as- ymptote of $95 \%$ CRs over 6 days with a 1.0-mA US was insufficient to produce the level of CRM previously obtained with a stronger ES or a strong AP (Buck et al., 2001). Our previous experiments showed that CRM was a function of the strength of conditioning (Schreurs et al., 1995), with the strongest levels of CRM occurring after 6 days of CS-US pairings. In those experiments, the most significant levels of CRM occurred at US intensities that were $25 \%-50 \%$ of the training intensity. In the present experiment, a similar trend appeared, although it could not be assessed statistically because of a lack of responding on pretest at those intensities. Specifically, 3 of the 8 paired rabbits responded to a US intensity of $0.25 \mathrm{~mA}$ on posttest, whereas none of these rabbits responded on pretest. Without responses by paired subjects on pretest or responses on either test by unpaired subjects, there was no way to assess the significance of the amplitude, peak latency, and area of URs to a posttest US intensity of $0.25 \mathrm{~mA}$.

To date, the strongest levels of CRM have been obtained following training to asymptotic levels in excess of
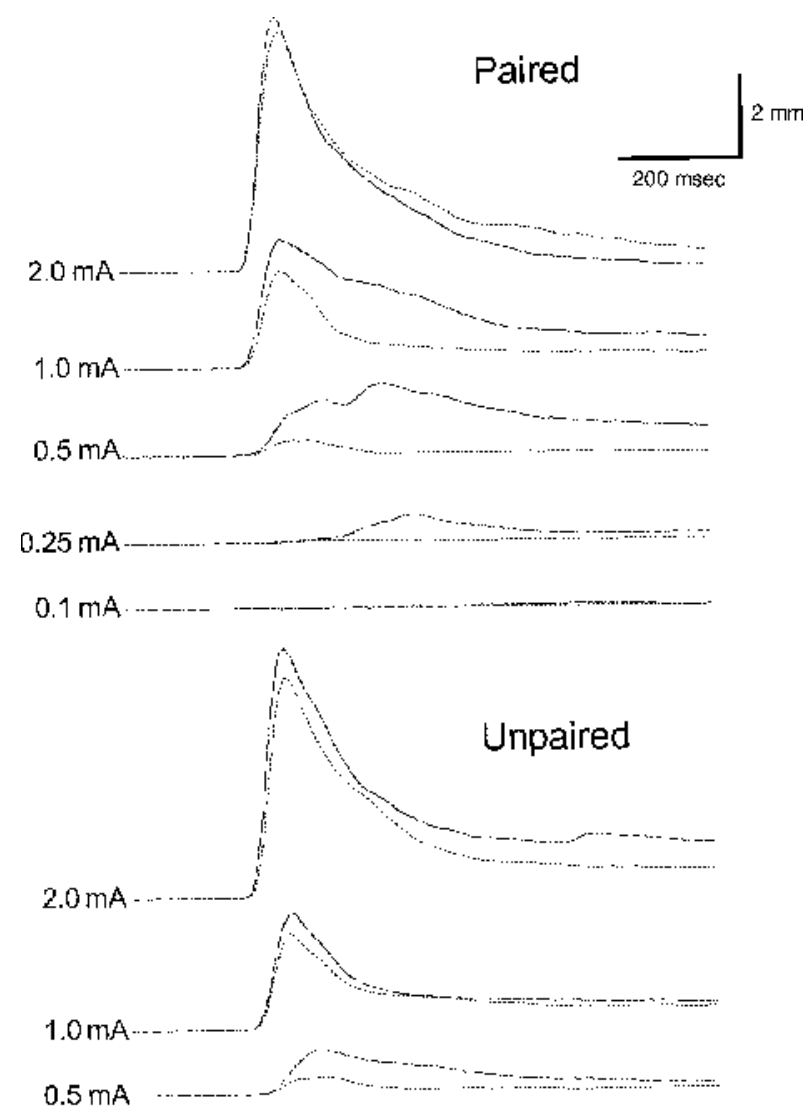

$0.25 \mathrm{~mA}$

$0.1 \mathrm{~mA}$

Figure 2. Averaged response topographies on US-alone pretest (dotted lines) and posttest trials (solid lines) for the paired and unpaired groups following six sessions with a $1.0-m A$ US. The plots are arranged in descending order of US intensity $(2.0 \mathrm{~mA}$ to $0.1 \mathrm{~mA}$ ) and collapsed across US duration. 
95\% CRs with a 2.0-mA US, and although the present data show that a $1.0-\mathrm{mA}$ US can support similar asymptotic levels of conditioning (see Figure 1), they suggest that it cannot support significant levels of CRM. Clearly, an asymptotic level of conditioning in excess of 95\% CRs with an effective US is not sufficient for obtaining effective CRM.

\section{EXPERIMENT 2}

Given the very modest levels of CRM following training using a 1.0-mA US, we conducted an experiment with a 2.0-mA US to replicate our original finding of CRM following 6 days of CS-US pairings (Schreurs et al., 1995) and to provide a contemporaneous data set with which to compare the current $1.0-\mathrm{mA}$ results.

\section{Method}

Unless otherwise noted, the apparatus and procedures were the same as those used in Experiment 1.

Sixteen rabbits were randomly assigned to two groups (paired, $n=8$, and unpaired, $n=8$ ) and received the same experimental treatment as in Experiment 1, except that the US intensity used during training was increased to $2.0 \mathrm{~mA}$.

\section{Results}

Conditioning. Figure 3 shows the mean $( \pm S E M)$ percent CRs for animals in the paired and unpaired groups across the 6 days of stimulus presentations. As can be seen, the paired animals showed a level of responding on the 1 st day of $45 \% \mathrm{CRs}$ and a rapid increase in CRs reaching an asymptote in excess of $98 \%$ CRs on Day 2. On the other hand, the unpaired animals showed virtually no sign of responding to the CS. An ANOVA revealed significant main effects of group and day $[F(1,14)=2,943.20, p<$



Figure 3. Mean $( \pm S E M)$ percent $C$ Rs for animals in the paired and unpaired groups across the 6 days of stimulus presentations with a 2.0-mA US. Note that all $S E M$ values are included but are often smaller than the data points.
.001 , and $F(5,70)=33.70, p<.001$, respectively], as well as an interaction of the two factors $[F(5,70)=31.22, p<$ $.001]$.

US testing. Figure 4 shows averaged response topographies on US-alone pretest (dotted lines) and posttest trials (solid lines) for the paired and unpaired groups. The plots are arranged in descending order of US intensity $(2.0 \mathrm{~mA}$ to $0.1 \mathrm{~mA}$ ) and collapsed across US duration. The figure clearly illustrates the CRM effect for paired subjects because responses on posttest were larger, peaked later, and had topographies that were shifted to the right in comparison with responses on pretest. In contrast, unpaired subjects showed no difference in responding between pretest and posttest. An analysis of skew and kurtosis for the paired subjects confirmed significant positive skew and kurtosis for all averaged pretest responses (skews $>3.6$, kurtoses $>2.7$ ), which, with the exception of the averaged response at $2.0 \mathrm{~mA}$, were no longer significantly positive or actually became significantly negative on posttest (skews $<-1.2$, kurtoses $<-3.4$ ).

Analysis of the mean UR frequency, onset latency, amplitude, peak latency, and area on pretest and posttest for the paired group clearly confirm the CRM effect with significant increases at the 0.5 -mA US intensity for UR amplitude $[F(1,11)=6.91, p<.05]$, peak latency $[F(1,11)=$ $13.94, p<.005]$, and area $[F(1,11)=14.68, p<.005]$, and also at the 1.0-mA US intensity for UR amplitude $[F(1,15)=7.93, p<.05]$, peak latency $[F(1,15)=12.23$, $p<.005]$, and area $[F(1,15)=7.90, p<.05]$. There was a significant increase in the frequency of responding at $0.25 \mathrm{~mA}[F(1,15)=22.13, p<.001]$ and $0.5 \mathrm{~mA}[F(1,15)=$ $21.63, p<.001]$. There were no significant differences between URs on pretest and posttest for unpaired subjects.

\section{Discussion}

The data from the present experiment provide clear evidence of a CRM effect following classical conditioning of the rabbit NMR with a 2.0-mA US (Buck et al., 2001; Schreurs et al., 1995; Schreurs et al., 2000). Responses on US posttest by paired rabbits became larger and response peaks occurred significantly later than on pretest, and, for that matter, than on pretest or posttest for the unpaired rabbits. Interestingly, the largest changes consistently appeared at $0.5 \mathrm{~mA}$ - an intensity that was $25 \%$ of the training intensity $(2 \mathrm{~mA})$. In the present replication of the CRM effect, the frequency of responding also increased at $0.5 \mathrm{~mA}$, indicating that CS-US pairings and the resultant high levels of classical conditioning not only changed the nature of the response but decreased the response threshold as well. Clearly, with a stronger ES serving as the training US, classical conditioning dramatically increased the rabbits' responsiveness to weaker values of the US in the absence of the CS.

\section{EXPERIMENT 3}

A comparison of the results of Experiments 1 and 2 indicated that CRM was a function of the intensity of the US 


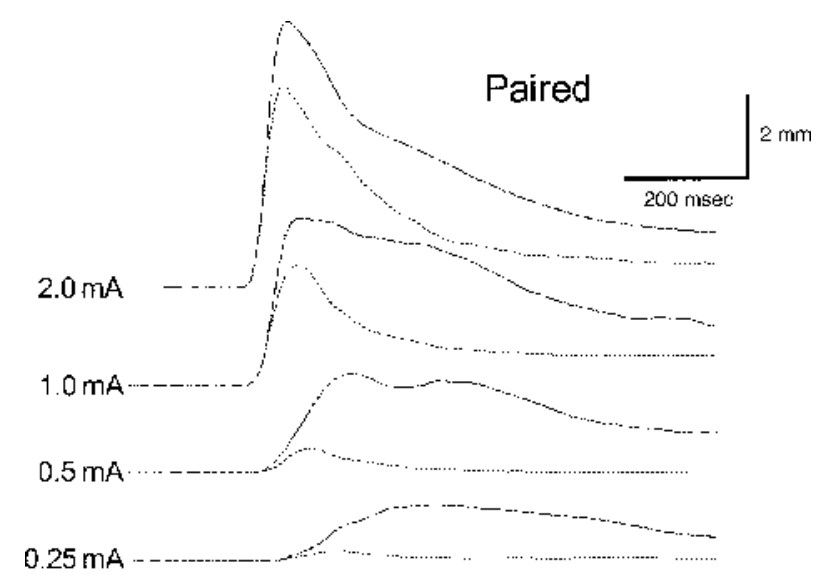

$0.1 \mathrm{~mA}$

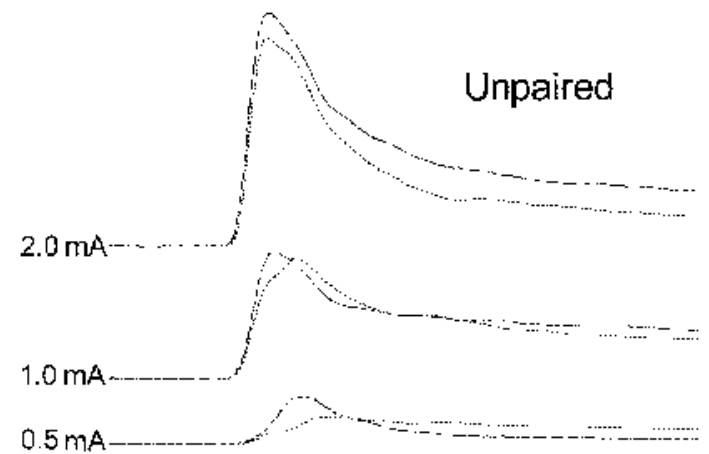

$0.25 \mathrm{~mA}$

$0.1 \mathrm{~mA}$

Figure 4. Averaged response topographies on US-alone pretest (dotted lines) and posttest (solid lines) trials for the paired and unpaired groups following six sessions with a 2.0-mA US. The plots are arranged in descending order of US intensity $(2.0 \mathrm{~mA}$ to $0.1 \mathrm{~mA}$ ) and collapsed across US duration.

used during CS-US pairings. Specifically, CRM was extremely modest at a $1.0-\mathrm{mA}$ training intensity but was quite strong at a $2.0-\mathrm{mA}$ training intensity. The present experiment was designed to determine whether the size of the CRM effect could be further increased by increasing the strength of the US used during training to $4.0 \mathrm{~mA}$.

\section{Method}

Unless otherwise noted, the apparatus and procedures were the same as those used in Experiments 1 and 2.

Twenty-three rabbits were randomly assigned to two groups ( paired, $n=12$, and unpaired, $n=11$ ) and received the same experimental treatment as in Experiment 1, except that the US intensity used during training was increased to $4.0 \mathrm{~mA}$

\section{Results}

Conditioning. Figure 5 shows the mean $( \pm S E M)$ percent CRs for animals in the paired and unpaired groups across the 6 days of stimulus presentations. As can be seen in the figure, the paired animals showed responding on the
1 st day of over $65 \%$ CRs and a rapid increase in CRs, reaching an asymptote in excess of $98 \%$ CRs on Day 2 . The unpaired animals showed virtually no sign of responding to the CS. An ANOVA revealed significant main effects of group and day $[F(1,21)=17,781.89, p<.001$, and $F(5,105)=80.43, p<.001$, respectively], as well as an interaction of the two factors $[F(5,105)=76.32, p<$ $.001]$.

US testing. Figure 6 shows averaged response topographies on US-alone pretest (dotted lines) and posttest (solid lines) trials for the paired and unpaired groups. The figure again illustrates the CRM effect for paired subjects, with responses on posttest peaking later and shifted to the right. In contrast, unpaired subjects showed no difference in response topography between pretest and posttest. An analysis of skew and kurtosis for paired subjects confirmed a significant positive skew and kurtosis for all averaged pretest responses (skews $>8.5$, kurtoses $>3.6$ ), which were no longer significantly positive or became significantly negative on posttest (skews $<1.2$, kurtoses $<-3.2$ ).

Statistical analysis of the mean UR frequency, onset latency, amplitude, peak latency, and area on pretest and posttest for the paired group show the CRM effect with significant increases in UR peak latency at US intensities of $0.25 \mathrm{~mA}[F(1,8)=14.28, p<.01], 1.0 \mathrm{~mA}[F(1,23)=$ $5.29, p<.01]$, and $2.0 \mathrm{~mA}[F(1,23)=5.77, p<.05]$; in area at US intensities of $1.0 \mathrm{~mA}[F(1,23)=5.52, p<.05]$ and $2.0 \mathrm{~mA}[F(1,23)=4.88, p<.05]$; and in the frequency of responding at $1.0 \mathrm{~mA}[F(1,23)=9.00, p<.01]$ and onset latency at $0.25 \mathrm{~mA}[F(1,8)=8.67, p<.05]$. Analysis of the unpaired data on pretest and posttest showed no differences, with the exception of an increase in the frequency of responding to the 0.5 -mA US $[F(1,21)=6.88$, $p<.05]$.

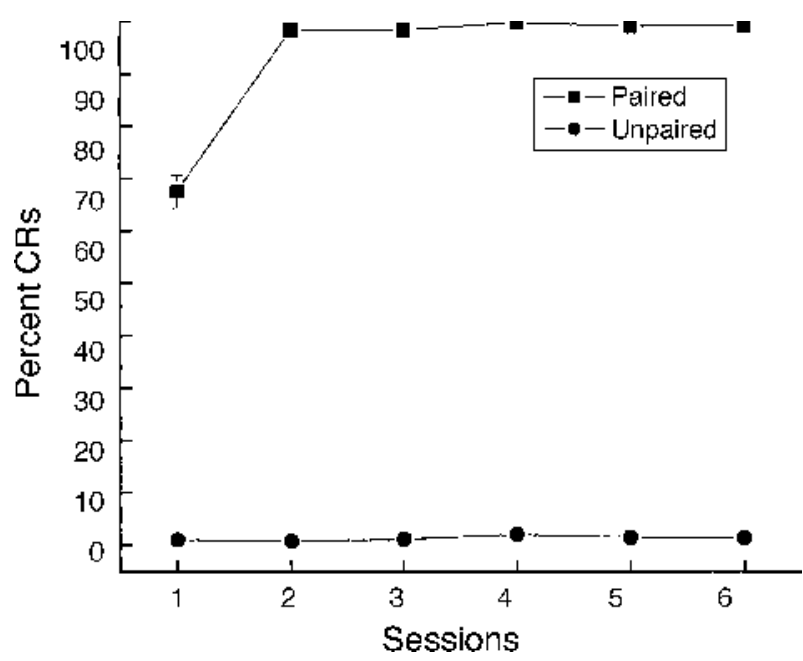

Figure 5. Mean ( $\pm S E M)$ percent $C R s$ for animals in the paired and unpaired groups across the 6 days of stimulus presentations with a 4.0-mA US. Note that all $S E M$ values are included but are often smaller than the data points. 


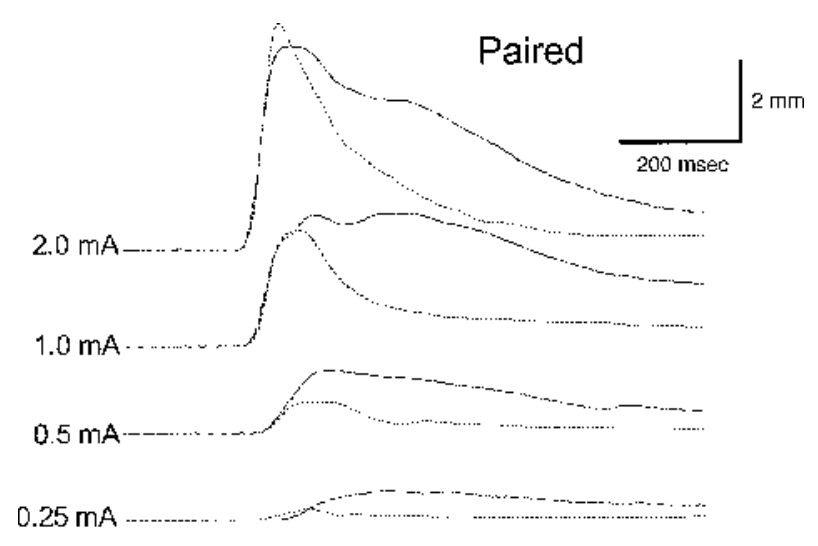

$0.1 \mathrm{~mA}$
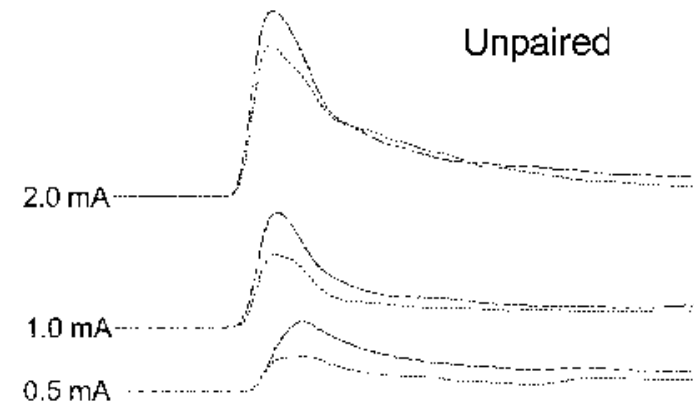

$0.25 \mathrm{~mA} \cdots \ldots \ldots$

$0.1 \mathrm{~mA}$

Figure 6. Averaged response topographies on US-alone pretest (dotted lines) and posttest (solid lines) trials for the paired and unpaired groups following six sessions with a 4.0-mA US.

\section{Discussion}

The results of the present experiment show that CRM could be obtained with a strong US and that the effect was most obvious as a shift in the size and peak of URs on posttest (Buck et al., 2001; Schreurs et al., 1995; Schreurs et al., 2000). Once again, the largest effects were at US intensities below the training intensity and in particular at a US intensity value that was $25 \%$ of the training intensity (significant increases in UR frequency, peak latency, and area at $1.0 \mathrm{~mA}$ ).

\section{GENERAL DISCUSSION}

Taken together, the present results show that CRM is a function of US intensity in the same way as classical conditioning is a function of US intensity (Fitzgerald \& Teyler, 1970; Gormezano, 1966; Smith, 1968). Thus, we can add this dependence of CRM on US intensity to the other characteristics of CRM.

However, as noted previously (Buck et al., 2001), there does not seem to be complete isomorphism between classical conditioning and CRM. This is illustrated here in the differences between them in the nature of their depen- dence on US intensity. Although there were significant differences in the initial level $(14 \%, 45 \%, 65 \% \mathrm{CRs})$ and rate of CR acquisition between each of the US training intensities in the present experiments (Tukey HSD, $p$ s $<$ .01 ), CRM was minimal after training with a 1.0-mA US and reached its maximum after training with a $2.0-\mathrm{mA}$ US. In other words, despite the fact that initial conditioning levels were a linear function of US intensity (MarshallGoodell, Kehoe, \& Gormezano, 1992), CRM appeared to plateau at a training US intensity of $2.0 \mathrm{~mA}$, perhaps indicative of a ceiling effect.

We have previously suggested (Buck et al., 2001) that the CRM phenomenon may be partly mediated by conditioned fear. In this and in earlier reports, higher intensity (and presumably more aversive) USs (e.g., strong AP and 2.0- and 4.0-mA ES) would lead to fear conditioning concurrently with conditioning of the NMR (McEchron et al., 1991). We will test this hypothesis in future experiments by measuring heart rate concurrently with the NMR. Not only would we expect to see heart rate changes associated with the conditioning phase of the experiment (bradycardia; Powell, 1994; Schneiderman, Smith, Smith \& Gormezano, 1966), but perhaps even altered heart rate responses to the US alone on posttest trials in paired animals (i.e., heart rate CRM; enhanced tachycardia). Future experiments will also assess the contribution of the conditioning context to CRM by changing the context between training and US testing.

We believe that our previous and present CRM data may have some implications for theories of and treatments for posttraumatic stress disorder (PTSD), a psychological disorder resulting from exposure to a traumatic event. The symptoms associated with PTSD include persistent reexperiencing of the traumatic event, persistent avoidance of stimuli associated with the trauma, numbing of general responsiveness, and persistent symptoms of increased arousal (Pitman, 1988; see Diagnostic and StatisticalManual of MentalDisorders, 1994 [DSM-IV]). One of the hallmarks of PTSD is intense psychological distress and/ or physiological reactivity to cues that symbolize or resemble an aspect of the traumatic event. This learningrelated aspect of PTSD has some similarities to the behavioral phenomenon outlined here and previously (i.e., CRM). Like a Vietnam veteran who "hits the deck" when he hears a car backfire, our rabbits now blink to a mild electrical stimulus as if it were a strong stimulus. However, in opposition to other conditioning accounts of PTSD (Brewin, 2001; Dobbs \& Wilson, 1960; Pitman, 1988), we would argue that the backfire is a weak "US" rather than a "CS."

The present data extend the connection between CRM and PTSD by indicating that conditioning may occur without CRM and that a conditioning episode needs to be relatively intense before CRM will occur. In short, only when events are sufficiently intense is there an exaggeration in how we later respond to less intense events. However, this does suggest that exposing patients to stressors in a controlled environment might extinguish the exaggerated responses in the same way as presenting the US by itself extinguishes CRM (Schreurs et al., 2000). 


\section{REFERENCES}

BREWIN, C. R. (2001). A cognitive neuroscience account of posttraumatic stress disorder and its treatment. Behaviour Research \& Therapy, 39, 373-393.

Buck, D. L., Seager, M. A., \& Schreurs, B. G. (2001). Conditioningspecific reflex modification of the rabbit (Oryctolagus cuniculus) nictitating membrane response: Generality and nature of the phenomenon. Behavioral Neuroscience, 115, 1039-1047.

Canli, T., Detmer, W. M., \& Donegan, N. H. (1992). Potentiation or diminution of discrete motor unconditioned responses (rabbit eyelid) to an aversive Pavlovian unconditioned stimulus by two associative processes: Conditioned fear and a conditioned diminution of unconditioned stimulus processing. Behavioral Neuroscience, 106, 498-508.

Coleman, S. R., \& Gormezano, I. (1971). Classical conditioning of the rabbit's (Oryctolagus cuniculus) nictitating membrane response under symmetrical CS-US interval shifts. Journal of Comparative \& Physiological Psychology, 77, 447-455.

Diagnostic and statistical manual of mental disorders (4th ed.) (1994). Washington, DC: American Psychiatric Association.

Dobis, D., \& Wilson, W. P. (1960). Observations on persistence war neurosis. Diseases of the Nervous System, 21, 686-691.

Donegan, N. H. (1981). Priming-produced facilitation or diminution of responding to a Pavlovian unconditioned stimulus. Journal of Experimental Psychology: Animal Behavior Processes, 7, 295-312.

Fit zgerald, R. D., \& Teyler, T. J. (1970). Trace and delayed heartrate conditioning in rats as a function of US intensity. Journal of Comparative \& Physiological Psychology, 70, 242-253.

Flaten, M. A., \& Powell, D. A. (1998). Conditioned-reflex facilitation in young and older adults. Experimental Aging Research, 24, 387-410.

Gormezano, I. (1966). Classical conditioning. In J. B. Sidowski (Ed.), Experimental methods and instrumentation in psychology (pp.385420). New York: McGraw-Hill.

Gormezano, I., \& GibBs, C. M. (1988). Transduction of the rabbit's nictitating membrane response. Behavior Research Methods, Instruments, \& Computers, 20, 18-21.

Gruart, A., \& Yeo, C. H. (1995). Cerebellar cortex and eyeblink conditioning: Bilateral regulation of conditioned responses. Experimental Brain Research, 104, 431-448.

IsON, J. R. \& LEONARD, D. W. (1971). Effects of auditory stimuli on the amplitude of the nictitating membrane reflex of the rabbit (Oryctolagus cuniculus). Journal of Comparative \& Physiological Psychology, 75, 157-164.

Marcos, J. L., \& Redondo, J. (1999). Effects of conditioned stimulus presentation on diminution of the unconditioned response in aversive classical conditioning. Biological Psychiatry, 50, 89-102.

Marshall-Goodell, B., Kehoe, E. J., \& Gormezano, I. (1992).
Laws of the unconditioned reflex in the rabbit nictitating membrane preparation. Psychobiology, 20, 229-237.

McEchron, M. D., McCabe, P. M., Green, E. J., Llabre, M. M., \& SchneIderman, N. (1991). Air puff versus shock unconditioned stimuli in rabbit heart rate conditioning. Physiology \& Behavior, 51, 195-199.

Nowak, A. J., Goodell-Marshall, B., Kehoe, E. J., \& GormeZANO, I. (1997). Elicitation, modification, and conditioning of the rabbit nictitating membrane response by electrical stimulation in the spinal trigeminal nucleus, inferior olive, interpositus nucleus, and red nucleus. Behavioral Neuroscience, 111, 1041-1055.

Pitman, R. K. (1988). Post-traumatic stress disorder, conditioning, and network theory. Psychiatric Annals, 18, 182-189.

Powell, D. A. (1994). Rapid associative learning: Conditioned bradycardia and its central nervous system substrates. Integrative Physiological \& Behavioral Science, 29, 109-133.

Schneiderman, N., Smith, M. C., Smith, A. C., \& Gormezano, I. (1966). Heart rate classical conditioning in rabbits. Psychonomic Science, 6, 241-242.

Schreurs, B. G., \& Alkon, D. L. (1990). US-US conditioning of the rabbit's nictitating membrane response: Emergence of a conditioned response without alpha conditioning. Psychobiology, 18, 312-320.

Schreurs, B. G., OH, M. M., Hirashima, C., \& Alkon, D. L. (1995). Conditioning-specific modification of the rabbit's unconditioned nictitating membrane response. Behavioral Neuroscience, 109, 2433.

Schreurs, B. G., Shi, T., Pineda, S. I., \& Buck, D. L. (2000). Conditioning the unconditioned response: Modification of the rabbit's (Oryctolagus cuniculus) unconditioned nictitating membrane response. Journal of Experimental Psychology: Animal Behavior Processes, 26, 144-156.

Sмiтн, M. C. (1968). CS-US interval and US intensity in classical conditioning of the rabbit's nictitating membrane response. Journal of Comparative \& Physiological Psychology, 66, 679-687.

WEISZ, D. J., \& MCINERNY, J. (1990). An associative process maintains reflex facilitation of the unconditioned nictitating membrane response during the early stages of training. Behavioral Neuroscience, 104, 21-27.

Weisz, D. J., \& WALts, C. (1990). Reflex facilitation of the rabbit nictitating membrane response by an auditory stimulus as a function of interstimulus interval. Behavioral Neuroscience, 104, 11-20.

Wikgren, J., Ruusvirta, T., \& Korhonen, T. (2002). Reflex facilitation during eyeblink conditioning and subsequent interpositus nucleus inactivation in the rabbit (Oryctolagus cuniculus). Behavioral Neuroscience, 116, 1052-1058.

(Manuscript received November 29, 2002; revision accepted for publication March 3, 2003.) 